Extrême-Orient Extrême-Occident

\section{Extrême-Orient Extrême-Occident}

$37 \mid 2014$

Penser les épidémies depuis la Chine, le Japon et la Corée

\title{
Measures against Epidemics during Late 18th Century Korea: Reformation or Restoration?
}

Mesures contre les épidémies au xviiie siècle en Corée : réforme ou restauration? 18 세기 후반 조선 국왕 정조의 홍역에 대한 대응 : 개혁인가, 복구인가?

\section{Dongwon Shin}

\section{OpenEdition}

Journals

Electronic version

URL: http://journals.openedition.org/extremeorient/333

DOI: 10.4000/extremeorient.333

ISSN: 2108-7105

\section{Publisher}

Presses universitaires de Vincennes

\section{Printed version}

Date of publication: 1 September 2014

Number of pages: $91-110$

ISBN: 978-2-84292-411-9

ISSN: 0754-5010

\section{Electronic reference}

Dongwon Shin, « Measures against Epidemics during Late 18th Century Korea: Reformation or Restoration? », Extrême-Orient Extrême-Occident [Online], 37 | 2014, Online since 01 September 2017 , connection on 19 April 2019. URL : http://journals.openedition.org/extremeorient/333 ; DOI : 10.4000/ extremeorient.333 


\title{
Measures against Epidemics during Late 18th Century Korea: Reformation or Restoration?
}

\author{
Shin Dongwon
}

\section{Introduction}

This article examines the nature of the national policies implemented by King Yi San (King Jeongjo; r. 1776-1800), to control hongyeok, literally "red epidemic," presumed to be measles in contemporary medicine, which was seen as the most fearful pediatric contagious disease during the Joseon Dynasty (1392-1910) in the 17th-19th centuries. The disease was called hongyeok, because a red rash developed all over the body, and it was also known as majin (hemp seed pox) because the rash resembled hemp seeds, which are even smaller than sesame seeds. Along with duchang (smallpox) and another disease vaguely classified as a yeok "pestilence," hongyeok became established as one of the three most common and most widely spread epidemic diseases. Terrible hongyeok epidemics would strike in cycles of 10-20 years from the mid-17th century onward. The first great outbreak was reported in 1668 and several hundred thousand people lost their lives to the disease in 1707, while the number of dead amounted to 10,000 in Seoul alone in 1730. The great epidemics of hongyeok which had killed more than ten thousand people in 1752 and 1775 were deeply engraved on the minds of contemporaries including King Jeongjo.

Yi San, regarded as a reformer king, reigned during the latter half of the Joseon Dynasty. On his enthronement, he established the Royal Library and Archives, where countless documents from home and abroad were collected and where he employed a great number of talented scholars. He continued the policy of impartiality implemented by his predecessor to reduce the ill effects of the chronic power struggles between the nation's political factions. He also started reform in diverse fields including agriculture, commerce, the military, and welfare, notably establishing "The Code for Famine Relief" (1783). He also made unprecedented attempts to obtain information from his subjects, and 
sought the advice of ministers of state, scholars and provincial administrators, on matters relating to national governance. This course of action, which would later include the "Royal Admonitions Recommending Agriculture and Seeking Agricultural Manuals" (1799), will be examined in detail in the present study. ${ }^{1}$

Early signs of an outbreak of hongyeok in the fourth month of 1786, 11 years after the previous epidemic, caused King Jeongjo to react. The methods he used to implement reforms throughout his reign were also evident in the national plans to control hongyeok. Drawing on different types of sources, we will shed light on the king's perceptions of this epidemic disease and on the policies he implemented to control it. The king's instructions and their implementation by the various government offices can be traced through the Jeongjosillok [Annals of King Jeongjo] and Ilseongnok [Records of Daily Reflections], which are very detailed daily logs. In addition to these sources that come from the central administration, there are also diary records from the civilian population such as the Heumyeong [Admiration for Excellence], the diary left by Yu Man-ju (1755-1788), who belonged to a prominent family in Seoul, the city in which the royal palaces were located; and the Ijaenan'-go [Rough Drafts of Master Ijae], the diary left by Hwang Yun-seok (1729-1791), who had just arrived in Seoul to work as a petty government official. These diaries, partly written during the epidemic, serve as alternative sources, offering an insight into how the central measures ordered by the monarch were actually implemented and how they were perceived by the population. By reviewing the interrelations among these records, the present study seeks to deepen our understanding of the national plans against, and civilian responses to, the 1786 hongyeok epidemic. It will thereby clarify King Yi San's response to the epidemic which also provided him with an opportunity to clearly demonstrate his commitment to protecting and promoting the people's well-being through good governance, and to frame himself as a Confucian benevolent ruler.

\section{The implementation of a system of thorough medical measures}

On day 12 of the fourth month, Yu Man-ju heard the Chief Minister reporting: "According to reports, the temporary symptoms are urgent and strange." The following day (the fourth month 13), he wrote in his diary: "hongyeok patients were found in the upper and lower servants'quarters attached to my house." On day 14 of the fourth month, at court, Chief Royal Secretary Yi Gyeong-yang proposed the preparation of medical measures:

1. Muhn Joong-yang 1995: 117-136. 
In recent days, hongyeok has spread throughout the capital and the provinces, but the simple and ignorant populace is not aware of formulas suitable for the disease. In terms of the court's obligation to show solicitude, there must be measures to relieve and save the people. In my opinion, it would be good to have the Medical bureau and the Public Dispensary devise prescriptions for suitable formulas and to promulgate them throughout the provinces. ${ }^{2}$

King Jeongjo ordered the court to discuss such measures, and, on day 20 of the fourth month, 6 days later, the results of the court's discussions were reported to the monarch. First, the point was raised that it was not appropriate for the Medical bureau (Jeonuigam) and the Public Dispensary (Hyeminseo) to devise the prescriptions for formulas and dispatch them to the provinces. ${ }^{3}$ The following reasons were invoked: there were not yet any reports from the provinces demanding measures against hongyeok; furthermore, as hongyeok was a disease that changed over time and with the seasons, and as living conditions and the people themselves differed from region to region, if people were taking medicine sent from Seoul "without being able to adapt them according to the symptoms," harm would result instead. ${ }^{4}$ Consequently, measures against hongyeok were limited to the capital and were assumed by the Government of Seoul. King Jeongjo issued the instruction that when there were appeals from those who were too poor to obtain medicine on their own, regardless of whether they were civil or military officials, commoners, or outcasts, the Medical bureau or the Public Dispensary was to dispatch medical doctors and provide medicine. Together with such measures, he gave 27,000 ansinhwan pills, which were pharmaceutical preparations for the royal household, to diverse offices and structures within the palaces so that they could be distributed widely. He also issued an order instructing that programs for the systematic implementation of measures against hongyeok were to be discussed, created, and submitted by the various government offices, including the Medical bureau, Public Dispensary, and Government of Seoul. ${ }^{5}$ The fact

2. Gugyeok Joseon wangjo sillok 1993: 564.

3. In 1109, in imitation of the Song Chinese tradition of treating the illnesses of the populace in which the "monarch bestows medicine as a virtuous deed for the populace," the Hyeminseo (Public Dispensary) was established to provide medicine to the inhabitants of the capital. This ideology of providing medical services to commoners was subsequently transmitted to the Joseon Dynasty, founded in 1392. The Joseon Dynasty established the Jeonuigam (the Medical bureau) separately from the public Dispensary, for the higher ruling class.

4. Gugyeok Joseon wangjosillok 1993: 565.

5. Gugyeok Joseon wangjosillok 1993: 565. 
that King Jeongjo ordered the provision of no fewer than 27,000 ansinhwan pills, which required many costly medicinal ingredients, was unprecedented and demonstrates that the king's measures were not mere posturing. In addition, the instructions to create operational programs expressed the will to respond to hongyeok by going beyond earlier practice.

On day 20 of the fourth month, according to King Jeongjo's instructions, the Medical bureau and the Public Dispensary, the two structures responsible for treating hongyeok, prepared and submitted "A Program for the Provision of Relief and Treatment for hongyeok" consisting of the following articles:

1.The areas assigned to the Medical bureau and the Public Dispensary: areas to the west of large roads in West Ward, North Ward, and Center Ward are assigned to the Medical bureau; and those to the east of large roads in East Ward, South Ward, and Center Ward are assigned to the Public Dispensary.

2. The dispatch and activities of medical doctors: the Medical bureau and the Public Dispensary each are to select three medical doctors skilled in the medical art, who then are to work all day at either office, inquiring about the symptoms in mild cases and paying visits, making examinations, and providing prescriptions and medicines in serious cases.

3. The objects and documentation of the provision of medicine: Medicine is to be provided only to the poor. Doctors'home visits and the provision of medicine are to be recorded in documents.

4. The promotion of the monarch's ordinances and "A Program for the Provision of Relief and Treatment for hongyeok": The Government of Seoul is to translate these into both written classical Chinese and han-geul [Korean Script] and to post them in villages. Upon the discovery of even a single person unaware of them, the officials in charge are to be held accountable.

5. The preparation of medicine including the necessary pills and decoctions: First, medicine is to be prepared from the funds of the Medical bureau and the Public Dispensary, and sufficient quantities are to be separately made up by the Office of Relief Works.

6. The prevention of dishonesty in the provision of medicine: When those who are not poor have received medicine through pretense, they are to be punished severely. In the case of patients, they are to report to government offices in advance and to provide confirmatory seals, which are to be used later as the grounds for receiving medicine when it is needed. It is because this measure is a very rare favor.

7. Compensations for medical doctors: In the case of medical officials who do not receive officials'salaries, provisions and food are to be provided according to "Guidelines on the Provision of Relief and Treatment for Infectious Diseases" of the Office of Relief Works. 
8. The reporting to superiors of documents on the provision of medicine: The medicine provided by the Medical bureau and the Public Dispensary is to be recorded every day, and statistics on the quantity used and the stock for 5 days are to be reported to the director.

9. The securement of horses solely for doctors' home visits: When medical officials are to pay home visits, the Board of War is to prepare one post horse each at the two post stations of Cheongpa Station and Nowon Station and even to supply provisions, thus having the officials ready day and night at the two medical offices.

10. The recording of hongyeok patients: The number of cases in which patients have been examined and the symptoms have been discussed, the number of pills and packages of medicine provided, and the number of cases in which medicine has not been used are to be recorded in detail, summarized, and reported at five-day intervals.

11. The permission to carry out private examinations by the medical doctors employed: When the medical officials dispatched have visited and attended to patients from the past, they are not to stop the private examinations due to the present work. However, they are not to use horses for official duties and are to be held accountable when they neglect their duties on the excuse of such private examinations.

12. The readiness of medical doctors: Because patients may arrive when medical officials from the Medical bureau or the Public Dispensary are on home visits, the latter are not all to be away at the same time, with one out of three medical officials standing by in turn. In addition, those who have been discovered outside these medical offices for reasons other than examining patients are to be punished severely. ${ }^{6}$

The Program for the Provision of Relief and Treatment for hongyeok thus encompassed the selection of the government offices for the treatment of hongyeok, the duties and tasks to be assumed by the medical doctors', the provision of medicine, the establishment of financial sources for the medicinal ingredients, support for the doctors'home visits, the promotion of the project, and the completion and reporting of documents and statistics. Put in modern terms, it was tantamount to the construction of an emergency medical relief system. Problems were revealed after only a few days. According to the first reports, submitted on day 27 of the fourth month, five days after the implementation, "During the five days, packaged medicine was provided in only several dozen cases and pills were provided to only several individuals."

6. Gugyeok Joseon wangjo sillok 1993: 565.

7. Gugyeokilseongllok 2001: vol. 57, 325-356. 
This did not conform to the original plan to make extensive medical visits and to save the lives of the populace. On investigation, it turned out that patients were not always examined by medical officials immediately, due to the procedure of having to be certified as patients at government offices. Suspect, too, was the negligence of medical officials at the Medical bureau and the Public Dispensary who were reluctant to work overtime. Furthermore, in one report, a number of medical officials gave the excuse of outside examinations, for not carrying out measures against hongyeok. Consequently, King Jeongjo stated and instructed, "The number of times that patients have been visited, examined, and inquiries made about their diseases likewise is negligible. Where, then, is the original intention for appointing medical doctors and preparing post horses? Once again admonish the two medical offices of this intention." At the same time, he ordered the abolition of the patient registration system. Severely criticizing these government offices'superficial execution of the measures against hongyeok, the monarch strongly urged them to manage the measures properly. ${ }^{8}$

Following King Jeongjo's order that reports were to be submitted every 5 days, reports on the number of patients and those treated and the provision of medicine were submitted up to 13 times. Thanks to such reports, specific statistics on the number of patients are available. ${ }^{9}$

Total number of cases examined and treated: 6,689 cases (Palace Medical bureau 2,232, Public Dispensary 4,457). Outpatients: 93.3\%, doctors'home visits: $6.7 \%$

Total number of hongyeok patients: 8,174 individuals (male children 4,766 (58.3\%), female children - 2,714 (33.2\%), male adults - $349(4.3 \%)$, female adults $-345(4.2 \%)$

Hongyeok peaked between the day 27 of the fourth month and day 2 of the fifth month, immediately after the first reports. It decreased considerably by day 19 of the sixth month, and then decreased gradually, to be eradicated around day 29 of the sixth month. In addition, as befits a pediatric infectious disease, most of those diagnosed as having the disease were children. However, there were no statistics on the number of deaths.

It is possible also to confirm the provision of medicines: 5,363 prescriptions were provided, 7,781 packages of medicine, 4,547 ansinhwan pills, and 825 ox bezoar unguent pills were distributed. Ansinhwan and ox bezoar unguents were among the very costly medicines bestowed on officials and female attendants

8. Gugyeokilseongllok 2001: vol. 57, 325-356.

9. Gugyeokilseongllok 2001: vol. 57, 325-326; vol. 58, 27, 37, 72, 117-118, 159, 213214, 260-261, 304-305. 
close to the king on year-end sacrificial rite days and their provision to the populace during times of infectious diseases was unprecedented. Initially, medical officials at the two medical offices tried to avoid dispensing this medication, but the medicine was provided as instructed after admonitions by King Jeongjo, who completed this unprecedented project, making use of his own personal wealth.

\section{An unprecedented royal request that remedies against hongyeok be sought throughout the country}

On day 22 of the fourth month, along with the proclamation of "A Program for the Provision of Relief and Treatment for hongyeok," King Jeongjo decreed that "Skilled doctors'treatments against hongyeok [were] to be obtained from Seoul and the provinces." 10 This, too, was unprecedented. It was usual for medical books or prescriptions prepared by royal doctors or medical officials to be transmitted downward to the people; ${ }^{11}$ but this was the first time that formulas would be presented from the people to the royal court. King Jeongjo's country-wide request to obtain effective remedies from all his subjects expresses the monarch's deep concern about the spread of the disease. This request also reveals the king's understanding of the disease:

In general, the outbreak of hongyeok is wholly due to the auxiliary climatic factors of the central movement, and the methods of treatment are not identical, and because the symptoms are already disparate, the ways of applying medicine differ likewise. Since days of yore, medical practitioners well-versed in the medical art have put evolutive phases and climatic factors first without fail, creating, before the outbreak of hongyeok, prescriptions to be used widely or creating, after the outbreak of hongyeok, and disseminating among the entire populace a single prescription by examining the annual fortune and taking the seasons into consideration. For hongyeok this year, too, is of a kind of evolutive phase and climatic factor, would not there be, among the countless in Seoul and the provinces who make a living with the medical art, ones such as these and others with such prescriptions? ${ }^{12}$

As this passage highlights, King Jeongjo shared the view that hongyeok stemmed from the five evolutive phases and six climatic factors. In other words, he felt it was due to the auxiliary climatic factors in the universal

10. Gugyeokilseongllok 2001: vol. 57, 304-306.

11. Shin, Dongwon 2004: 53-54.

12. Gugyeokilseongllok 2001: vol. 57, 304-306. 
central movement that hongyeok broke out in years such as the imsin (in Chinese, Renshen) year (1776) and the byeong-o (in Chinese, Bingwu) (1786). As King Jeongjo mentions, past and contemporary medical practitioners were deeply concerned with the periodicity of hongyeok, which in its early stages, was reported as generally spreading in 10-year or 12-year periods. Today, such a phenomenon is explained in terms of herd immunity theory (community immunity). After an epidemic, among survivors, those who have been ill acquire immunity and consequently the number of carriers necessary for a new epidemic is small, thereby preventing an epidemic for some time. However, newborn children have no immunity and as the number of children born after the epidemic increases so does the possibility of a new outbreak, and this process is repeated subsequently. During the 18th century, people viewed the disease's periodicity as being related to the heavens, or to the movement of the twelve earthly branches (sib-iji in Korean, shierzhi in Chinese) and the ten heavenly stems (sipgan in Korean, shigan in Chinese). In their view, each heavenly stem and earthly branch corresponded to one of the Five Phases (wood, fire, earth, metal, and water) and to one of the six climatic factors (wind, cold, heat, dampness, dryness, and fire), and, as the ten heavenly stems and the twelve earthly branches went in circles and alternated places, the rise and fall of a particular force changed. Contemporaries thus believed that the forces affecting the human body continuously changed during such cycles and, as a result, specific diseases developed more easily in specific years. If one could understand this principle, they claimed, it would then become possible to prepare formulas that would control a particular force. To King Jeongjo's thinking, because the evolutive phases and the climatic factors were circulatory by nature, it was thus possible to prepare formulas in advance, and then tailor them according to the particular force influencing the outbreak, and use them when the disease struck.

Underlying King Jeongjo's measure of searching countrywide for doctors well-versed in the medical art and formulas, was the idea that, due to inexperience, the medical officials in Seoul were unable to present effective formulas against hongyeok. As already noted, hongyeok was a disease that was known to disappear after cycles of ten or more years. Research on this disease was usually neglected by medical doctors. In Magwahoetong (A Comprehensive Treatise on the majin, 1797), Jeong Yag-yong explained why:

It is sad. It has been a long time since the sick have lacked medical doctors. Although this holds true of all diseases, it is even more severe in the case of hongyeok, and what may the reasons be? Those who make their living as medical doctors do so to make a profit. As there is usually only one outbreak every twelve years or so they 
don't bother to learn how to treat hongyeok, because there is no money in it. It is shameful that those who make a living from medicine do not study this disease, and also shameful to treat someone with hongyeok as it is, alas, cruel to use medicine by conjecture and thus to cause someone's death. ${ }^{13}$

King Jeongjo's perception was identical. He therefore issued an order targeting the entire population: "If there are those who are well-versed in evolutive phases and climatic factors and have created formulas, they are to submit [the formulas] to headquarter towns regardless of whether they are aristocrats or provincial rank-holders, whether their formulas are ancient or modern, and [the formulas] are to be transmitted to government offices in Seoul." ${ }^{14}$ Public notices posted in Seoul and dispatched to the provinces reported:

\begin{abstract}
Scholars in Seoul and the provinces who make a living with the medical art are ashamed to boast of themselves, and the outcasts who have secret formulas find it difficult to present themselves voluntarily. In hindering the transmission of such formulas they are defying the king's wishes to make enquiries from the populace. At one time in days of yore, lost books were sought and those who found them were bestowed with government posts. If there are good formulas that will allow the populace to enjoy their natural spans of life and are proven to be clearly effective, how would the merits be comparable to those of finding and presenting lost books? ${ }^{15}$
\end{abstract}

Only a month or so after the issuance of the order to obtain formulas for hongyeok, the Jingyeokbang (Formula against hongyeok) by Bak Sang-don, a Confucian scholar in Chilgok, Gyeongsang Province without an official title, and formulas submitted by Nam Gi-bok, an aristocrat in Jincheon, North Chungcheong Province, were presented. ${ }^{16}$ The Medical bureau and the Palace Pharmacy examined them and found that they were Chinese formulas against hongyeok. Bak Sang-don's formula was judged more reliable and therefore was chosen, printed and dispatched to each province on the fifth month $29 .{ }^{17}$

King Jeongjo's requests for plain counsel from his subjects are measures unseen during the reigns of earlier monarchs. Over ten years later, he would again request scholars nationwide for plain counsel from his subjects regarding

13. Jeong Yag-yong1934-1938: 286-413a.

14. Gugyeokilseongllok 2001: vol. 57, 304-306.

15. Gugyeokilseongllok 2001: vol. 57, 304-306.

16. Gugyeokilseongllok 2001: vol. 57, 325-326.

17. Gugyeokilseongllok 2001: vol. 58, 191-201. 
agriculture. This method, then, was first used during hongyeok in 1786, for the first time in the history of the Joseon Dynasty.

\section{The expansion of the scope and the strict implementation of the sacrificial rites to the demons of pestilence}

While we have focused on the monarch's deep concern in providing medical care to the populace, the first measure against the outbreak of hongyeok was, however, not the medical measures examined above but the performance of sacrificial rites to the demons of pestilence, and to the gods of epidemic diseases. On the 10th day of the fourth month, while the court was pondering measures against hongyeok and ten days before the implementation of medical measures, King Jeongjo ordered the immediate performance of sacrificial rites to the demons of pestilence. ${ }^{18}$

Undocumented up to the Goryeo Dynasty (918-1392), sacrificial rites to the demons of pestilence were institutionalized in 1403, immediately after the foundation of the Joseon Dynasty, on the model of Ming China's "Ritual System in the Hongwu Era" (1370). ${ }^{19}$ The "Ritual System in the Hongwu Era" includes the following:

(According to the Emperor's imperial edicts)... Without being offered sacrificial rites, such spirit have no place to rely on so that the spirits condense instead of dispersing and thereby become spirits of the dead. While some dwell in trees and grass, others turn into ghosts, crying out plaintively on moonlit nights and wailing during rainstorms. In general, when they encounter [living] people, they desperately long for the bright world, but their spirits are far-off and have nowhere to return to. Whereas the bodies rot, flung down in the streets, the minds anxiously wish for sacrificial rites. Having thus spoken, I cannot hide my sentiments of pity out of sorrow (for the ghosts). I therefore have admonished Confucian scholars across the country and commanded them to hold sacrificial rites according to seasonal sacrificial rites and the tutelary gods of the main areas to preside over (the sacrificial rites)..$^{20}$

The objects of sacrificial rites to the demons of pestilence were spirits of the deceased who had not been offered a proper funerary rite. They were believed to turn into vengeful spirits and to cause various disasters, particularly

18. Gugyeokilseongllok 2001: vol. 57, 244-246.

19. Yi Uk 2009: 301-306.

20. Yi Uk 2009: 307. 
epidemic diseases. In Ming China the tradition of holding sacrificial rites for spirits who had not been offered a proper funerary rites also included folk and Daoist tutelary gods who served to monitor unjust deaths in their respective areas and the good and evil deeds performed by the living. In Ming China, sacrificial rites to tutelary gods were held in the capital, state sacrificial rites to the demons of pestilence were held in provinces, county sacrificial rites to the demons of pestilence were held in cities and major prefectures, and town sacrificial rites to the demons of pestilence were held in lesser prefectures. An altar had been created to the north of the Korean capital and sacrificial rites to the demons of pestilence were performed. ${ }^{21}$ In the Joseon, regulations on sacrificial rites to the demons of pestilence were established according to Gukjo Oryeui (the Manual of the Five State Rites, 1474, in the 5th year of King Seongjong's reign). According to these regulations, sacrificial rites to the demons of pestilence consisted of two rites: sacrificial rites to tutelary gods and sacrificial rites to the demons of pestilence. In addition, the altars were placed in the East, West, South, and North of Seoul. The ceremonies included different sequences: first, three days before the sacrificial rites to the demons of pestilence, the rites of announcement were held, where tutelary gods were to be informed at the South Altar of the prospective date of the sacrificial rites. Three days later, the sacrificial rites to the demons of pestilence, namely the main ceremony, were to be held at the North Altar. The spirit tablets of tutelary god were brought in and arranged at the North Altar, facing the South Altar; those of the fifteen kinds of spirits who had not been offered a proper funerary rite, who were lower than tutelary gods, in the divine hierarchy, were arranged below the altar, on the right and left sides, facing one another. ${ }^{22}$ The fifteen spirits honored those who had died one of the fifteen unjust deaths - in cart accidents, on the battlefield, by drowning, etc. Without these rites, these deceased souls, unable to rest or enter the underworld would become vengeful ghosts, able to infect individuals and communities with contagious diseases. ${ }^{23}$

King Jeongjo sought to strictly implement the ritual system relating to the performance of sacrificial rites to the demons of pestilence. This meant the restoration of all elements originally implemented during the reign of the Ming Emperor Hongwu (Taizu) but not continued in the Joseon dynasty. According to the king Jeongjo's orders, incense was to be collected on a selected day one or two days before the sacrificial rites to the demons of pestilence; tutelary gods were to be informed without fail; after performing the rites of announcement to

21. Yi Uk 2009: 307-311.

22. Yi Uk 2009: 305.

23. Yi Uk 2009: 299-386. 
tutelary gods, hitherto omitted, the sacrificial rites to the demons of pestilence, hitherto performed only at the altar to the north, were to be performed in the four wards and the center of Seoul; and all provincial towns likewise were to hold the sacrificial rites. ${ }^{24}$ The monarch then instructed the composition of ritual invocations by the Yebu (Office of Royal Decrees) to be used as follows; by the state ritual officiators who presided over the sacrificial rites in the capital, by senior statesmen who were to be dispatched in the case of altars to tutelary gods and by officials with the 4th and higher court ranks who were to be selected and dispatched in the case of altars to the demons of pestilence. ${ }^{25}$

In addition, King Jeongjo personally composed ritual invocations such as the one below:

While there are a hundred gods in the realm, our tutelary god is placed at the head, and only it can command disasters and auspices. (It turns disasters into auspices.) Though sinister energy has been swept away widely and the epidemic disease has been driven back (all the times), putting around thousands of miles, how was the stirring up of eruptions in people made to start (itself) in spring? When demons of ill-health seized the fire, many of the people fell ill. While it must be guaranteed that there are no disasters of deaths, how is it that the people are gradually infected? If men and gods are to be seen equally, gods oversee the lives of my people, (they say that I am the lord of taking charge of lives of people) the range of Mt. Mang [a mountain in China often used as a figure for burial grounds] extends far, and widely watches over new lands. Lastly, forming the netherworld, leads every (frustrated) spirit to return to supreme harmony. To offer sacrificial rites with clean offerings, I have chosen an auspicious day (morning) and thus call out loudly. It is a wide and distant field, and I prompt them to arrive from all directions and to eat and drink their fill, and there are ceremonial vessels made of earth and wine jars made of baked earth. For, last night, a great rain fell and cleanly washed away the sinister energy and pestilence, allowing them to enjoy longevity. Save my people for years to come..$^{26}$

Whether this ritual invocation to the demons of pestilence is specifically related to hongyeok remains uncertain. As the invocation assumes the form of rites to the demons of pestilence at the altars in the four suburbs, and not only at the North altar, it presumably dates from this or a later period. It is possible to read in this ritual invocation King Jeongjo's wish, as national ruler, to resolve

24. Gugyeokilseongllok 2001: vol. 57, 244-246.

25. Gugyeokilseongllok 2001: vol. 57, 244-246.

26. Yi, San 1998: a_262_328c. 
the disaster that had befallen the country. Indeed, it was rare for a monarch personally to compose a ritual invocation. Only the ritual invocations to the demons of pestilence composed by King Jungjong (r. 1506-1544) are known.

In focusing on measures to restore the old forms of the sacrificial rites to the demons of pestilence, one must not overlook the fact that King Jeongjo's performance of sacrificial rites to the demons of pestilence with respect to hongyeok reflected innovation: this was the first time that sacrificial rites to the demons of pestilence were held for the epidemic disease known as hongyeok. The monarch stated: "Because, out of cases from the past there are but few that can be used precisely as authorities, there is no reason not to establish the system after consideration now." ${ }^{27}$ Originally, the epidemic diseases for which sacrificial rites to the demons of pestilence were held included pestilence onyeok (warm epidemic), and dangdokyek (poisonous plague from Tang). Neither smallpox duchang nor hongyeok, characterized by abnormal symptoms on the skin, had been the object of sacrificial rites to the demons of pestilence. However, King Jeongjo included hongyeok among the objects of sacrificial rites to the demons of pestilence, arguing: "As it is said that there is a very severe outbreak of hongyeok now, the people must be concerned about infection. How, then, can one sit and just wait until the disease disappears completely? The sacrificial rites praying for the eradication of hongyeok cannot wait a moment longer." 28 This provides us a glimpse of the monarch's style of governance; in order to protect his people, he went against convention.

\section{How did the civilian population consider the measures against hongyeok?}

The measures taken against the hongyeok epidemic in 1786 highlight how King Jeongjo made the provision of costly medicinal ingredients to the impoverished populace possible with money from his personal wealth. In addition, he established thorough guidelines for the hongyeok prevention project, thus facilitating the hongyeok prevention activities of the Medical bureau and the Public Dispensary. Statistics on diagnosed sufferers were submitted on a strict five-day basis, and at the monarch's request, efforts were made to acquire the latest medical information countrywide. Likewise, another measure against epidemic diseases, sacrificial rites to the demons of pestilence, was used against hongyeok for the first time in history and held after the

27. Gugyeokilseongllok 2001: vol. 57, 244-246.

28. Gugyeokilseongllok 2001: vol. 57, 244-246. 
restoration of strict adherence to the traditional rituals. How, then, were such measures received by the civilian population? While there are no historical materials that reveal the entire situation, a fragment can be surmised through the contents of Yu Man-ju's diary Heumyeong (Admiration for Excellence) and Hwang Yun-seok's diary Ijenan'-go (Rough Drafts of Master Ijae).

Both records express interest in the monarch's issuance of an order to obtain formulas against hongyeok from the farthest reaches of his kingdom. On the very day that this measure was announced, Yu Man-ju recorded in his diary: "Because there has been a great outbreak of hongyeok, the king has issued an instruction for the provision of formulas from skilled doctors in Seoul and the provinces" (the 22nd day of the fourth month). ${ }^{29}$

Hwang Yun-seok likewise wrote on the 27th day of the fourth month, three days after Yu Man-ju: "Because there have been great outbreaks of hongyeok in recent days, the king has been concerned and issued an order, far and near, for a wide search throughout the country for secret formulas and recommendations from skilled doctors and their special." 30 This diary shows that the order was promptly transmitted not only to the capital but also to the provinces through the regional administrative network, and, as a result, many formulas were submitted. The countrywide and unprecedented search for formulas launched by the King was of considerable interest at least to scholars, whose participation had been requested by the monarch.

These two diaries do not express much interest in the ruler's other measures. What attracted the attention of these two scholars was the disease's appearance at the court. On day 3 of the fifth month, 1786, the crown prince, the heir to the throne, began to show symptoms of the disease whose development was recorded with great interest in these diaries, almost hour by hour as if in a real-time broadcast. Indeed, in dozens of entries, the two diaries vividly record the progress of the crown prince's illness until his death. News on the crown prince's contraction of hongyeok and death were thus transmitted to the residents of the capital moment by moment. In fact, the king, queen, and crown prince were the object of constant public scrutiny, not least because their complete recovery from illnesses were often followed by measures of favor such as the remission of taxes and the release of minor offenders or by holding special state service examinations. Yu Man-ju's diary precisely records that extraordinary examinations had been planned in Seoul (the 7th day of the fifth month), in celebration of the crown prince's hoped for recovery. ${ }^{31}$

29. Yu, Man-ju 1993: vol. 6, 213.

30. Hwang, Yun-seok 1994: vol. 7, 216.

31. Yu, Man-ju 1993: vol. 6, 222. 
Although King Jeongjo made unprecedented efforts, the provision of costly medicines and the strict procedures for the examination and management of patients went unnoted by both Yu Man-ju and Hwang Yun-seok. While there were hongyeok patients in Yu Man-ju's household, they were unaffected by the measures taken by the court because the family was not poor. To treat hongyeok patients in the family including his own son, Yu Man-ju personally visited a private medical doctor and purchased medicine at a pharmacy. As for Hwang Yun-seok, because he was away from his family, was alone in Seoul and had not contracted hongyeok himself, King Jeongjo's medical measures did not apply to him, even if his diary bears testimony that he was very anxious that young children in his family might contract the disease.

Hwang Yun-seok's diary contains another important narrative that sheds light on an outcasts'perception of hongyeok. On the 13th day of the fifth month, the day after the crown prince's death, a slave known as Jeong came to the capital from the diarist's native town of Heungdeok. Regarding the deaths of those of noble births, this man explained his views:

As I was traveling to Seoul and passing by Seonghwan Post Station, I heard that there were cases of baby hongyeok. Since spring, there has been smallpox in Seoul, then hongyeok immediately afterwards, and many died because, after hongyeok had been cured, there still remained great pain due to heat and roundworms among the people. In the world, those who could not afford medicine were happy, while the high officials who had a lot of medicine deteriorated so that countless died violently from remaining symptoms such as strong headaches as if the head was struck, extreme fits, blank stares, and mere words. With this illness, it was possible to save lives only with a common distilled liquor, sojo [folk alcohol drink] and dried meat. (13th day of the fifth month.) $)^{32}$

The slave's words saying that among the public, those who did not get medicine actually were fortunate, while the high officials who had much medicine, met with ruin are paradoxical in a sense. The idea that having a good stock of medicine is not always helpful and that only sojo and dried meat and fish are sufficient reflect the idea that while they might (always) be deficient in medicine, their lot, need not be pitiable. It is difficult to find the voices of other slaves in Joseon's medical records that would confirm Jeong's viewpoint. An account like Joeng's was a very rare case since most records of the time were from the elite class. However, it suggests that opinion may have been divided

32. Hwang, Yun-seok 1994: vol. 7, 258. 
on the benefits of the monarch's actions, and notably on his bestowal of costly medicine on his people.

Neither of the two diaries mentions the implementation of the strict sacrificial rites to the demons of pestilence, for which King Jeongjo expended considerable and unprecedented effort. While, as a ruler, he attached much significance to the reestablishment of more complete rites than had been practiced under more recent monarchs and the performance of sacrificial rites to the demons of pestilence with respect to hongyeok, the acts do not seem to have greatly impressed scholars and the populace. The sacrificial rites to the demons of pestilence are likely to have been perceived as routines performed by the king or regional magistrates. In other words, they failed to attract attention because they were changes, no matter how considerable, within routines. Rather, the citizens of Seoul, like Hwang Yun-seok, had another perception of the causes of the outbreak of the epidemic: "The diverse symptoms of hongyeok are thus severe because people relocated graves in March a taboo in the old days, but do not abide by it now" (Hwang Yun-seok, day 27 of the fourth month). ${ }^{33}$ While spirits who had not been offered proper funerary rites had become established as symbolic entities in routines, the citizens of Seoul were considering the more direct reason that the disease was the work of vengeful spirits due to the violation of a taboo and the relocation of graves.

\section{Conclusion: innovation or restoration?}

The 1786 hongyeok epidemic passed without great loss of life. Whether this was due to King Jeongjo's measures against hongyeok is questionable. Although it is difficult to determine the actual reasons, the disease weakened in Korea after 1775 and there were no longer terrible epidemics as in the past.

Two coexisting views on the causes of these epidemics can be seen in King Jeongjo's actions. One came from the medical theory of the five evolutive phases and six climatic factors. As diseases were believed to assume periodicity according to the movement of celestial forces, these epidemics could be countered by understanding the motions of the cosmos and preparing suitable formulas in advance. Based on such thinking, the king issued orders to obtain formulas from around the country. The second came from the longstanding beliefs about the role of demons in the spread of epidemic diseases: vengeful spirits who had not been offered proper funerary rites were believed to cause epidemic diseases. As a consequence of this perception, epidemic diseases

33. Hwang, Yun-seok 1994: vol. 7, 216. 
could be resolved by placating those vengeful spirits. King Jeongjo expanded this thinking to include the disease known as hongyeok and sought to obtain the desired effect by restoring a stricter observation of the traditional rituals devoted to appeasing these spirits. This epidemic disease, which, in the eyes of the monarch, could be explained by natural and supernatural forces, at the same time, provided him the opportunity to demonstrate his ability to embody the most esteemed values of Confucian political thought and to shape himself as a benevolent ruler by excellence, a condition for authority.

As mentioned earlier, King Jeongjo sought to demonstrate the proper norms of governance in all fields. To him, this signified the realization of the Confucian ideology as shown by ancient sages. The epidemic gave him the opportunity to reactivate these norms in the medical field, which, as this contribution shows, consisted in restoring the ancient sacrificial rites to the demons of pestilence as well as implementing emergency relief measures including the bestowal of costly medicine and a strict control over medical administration. The tradition of dispatching medical doctors or medicine to places plagued by epidemic diseases had been implemented since the early years of the Joseon Dynasty and was also stipulated in the legal codes. In this respect, it is possible to say that King Jeongjo's methods were not entirely new. Nevertheless, whether such actions led to the actual provision of medical aid or remained mere words depended on who the monarch was. The case of King Jeongjo seems exceptional since his measures did not stop at formal measures but rather encompassed the exploration of other methods not attempted by previous rulers. His expansive politic did not stop at the provision of medicine to the populace through government medical structures such as the Medical bureau and the Public Dispensary, but also included making costly medicines such as ansinhwan. This spirit of selfless dedication is also evinced by the operation of an emergency system using post horses, a strict 5-day report system, direct and unceasing concern for medical administration even in the face of his own son's death; and the unprecedented step of making direct inquiries to his ministers and people for formulas against hongyeok. All of these measures are difficult to find in the policies of earlier monarchs and helped grant King Jeongjo, like the earlier King Sejong (r. 1418-1450) from the first half of the Joseon Dynasty, the status of an enlightened monarch. Similarities can also be confirmed in the case of the implementation of sacrificial rites to the demons of pestilence, which were complementary responses to hongyeok. Implemented as a measure against epidemic diseases since the first years of the dynasty, sacrificial rites to the demons of pestilence were not in themselves new. However, King Jeongjo did not follow established practice. Instead of allowing the procedures of sacrificial rites to the demons of pestilence to be 
implemented in a reduced form, he ordered that the full ceremonies stipulated by the Ming Ritual System in the Hongwu Era (Hongwu Lizhi) were strictly followed. In contrast to his forebears, he boldly included hongyeok as an object of the sacrificial rites which had not previously been encompassed by sacrificial rites to the demons of pestilence. Moreover, he personally composed ritual invocations to the demons of pestilence, something that was uncommon for earlier monarchs. Through these measures, King Jeongjo clearly demonstrated his commitment to protecting and promoting the people's well-being, framing himself as a Confucian benevolent ruler.

Finally, do the measures taken against hongyeok during the of King Jeongjo's reign qualify as being innovative or reformative? When seen macroscopically, the measures against hongyeok taken by the ruler were in part inherited and yet in other areas far exceeded previous methods. Scholars who seek to find modernity in King Jeongjo's rule will perhaps call this an "innovation." Innovation appears clearly in the unprecedented provision of medicines and the unprecedented acquisition of information, and even in the extension of the religious rituals against epidemics to include new epidemic diseases such as hongyeok. To render measures according to the theory of ghosts more thorough, old institutions were revived and extended. King Jeongio's "innovation" encompassed not only the implementation of new ideas, but also the restoration of underlying traditions. 
Measures against Epidemics during Late 18th Century Korea

\section{BibLIOGRAPHY}

Gugyeok Joseon wangjosillok 國譯朝鮮王朝實錄 (Korean Translation of the Annals of the Joseon Dynasty) (1993). Seoul, Sejong saeop ginyeomhoe.

Gugyeokilseongllok 國譯日省錄(A Korean Translation of Records of Daily Reflections) (2001). Seoul, Minjok munhwa chujinhoe.

HwANG Yun-seok (1994). Ijaenan'go 頣齎亂营 (Rough Drafts of Master Ijae). Seoul, Han'guk jeongsin munhwa yeonguwon.

JEONG Yag-yong (1937-1938). Magwa hoetong 麻科會通 (A Comprehensive Treatise on the majin) Yeoyudang jeonseo 與猶堂全書 [All Books of Yeoyudang], Keijō, Shinchōsen-sha.

MuHN Joogn-yang (2005). Joseon Hugiui 'Surihak' 朝鮮 後期의 水利學 (The HydroAgricultural Knowledge in the Late Choson Korea). P.H. Dissertation, Program of History of Science and Philosophy, Seoul National University.

SHIN Dong-won (2004). Hoyeolja, Joseon-eul Seupgyeokhada: Mom gwa Uihak-ui Han-guksa 호열자 조선을 습격하다 몸과 의학의 한국사 (Cholera Raids Joseon: A Korean History of the Body and Medicine). Seoul, Yeoksabipyeongsa.

YI Uk (2009). Joseon sidae jaenan gwa gukga Uirye 조선시대 재난과 국가 의례 (Disasters and State Rites during the Joseon Dynasty). Seoul, Changbi.

YI San (1998). Gugyeok Hongjae jeonseo 國譯弘齋全書 (A Korean Translation of All Books of Hongjae). Minjokmunhwachujinhoe.

Yu Man-ju (1993). Heumyeong 欽英 (Admiration for Excellence). Seoul, Seoul Daehakyo Gyujang'gak. 
Shin Dongwon

\section{GLOSSARY}

Ansinhwan 安神丸

Bak, Sang-don 朴合敦

Byeongo 丙午 Bingwu (in Chinese)

Dangdokyeok 唐毒疫

Duchang 痘瘡

Goryeo (Dynasty) (918-1392) 高麗 (王朝)

Gukjo Oryeui 國朝五禮儀

Gugyeok ilseongnok 國譯日省錄

Heumyeong 欽英

Hongwu Lizhi 洪武禮制

Hongyeok 紅疫

Hwang Yun-seok 黃胤錫

Hyeminseo 惠民署

Ijaenan-go 頣齎亂菜

Imsin 王申 (Renshen, in Chinese)

Jeonuigam 典醫監

King Jeongjo 正祖

King Sejong 世宗

Jeongjosillok 正祖實錄

Jinyeokbang 疹疫方

Joseon (Dynasty) (1392-1910) 朝鮮 (王朝)

Majin 麻疹

Magwa hoetong 麻科會通

Nam, Gi-bok 南紀復

Onyeok 瘟疫

Sipgan 十干 (shigan, in Chinese)

Sib-iji 十二支 (shier zhi, in Chinese)

Sojo 燒酒

Yebu 禮部

Yeojemun 庽祭文

Yeok 疫

Yu Man-ju 兪晚柱 